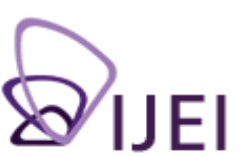

International Journal for Educational Integrity

\title{
Review
}

\section{The uses of digital literacy}

\author{
John Hartley (2009) \\ St. Lucia, QLD: University of Queensland Press.
}

\author{
Katharina Freund \\ University of Wollongong. \\ kfreund@uow.edu.au
}

\begin{abstract}
John Hartley's The Uses of digital literacy (2009) is the respectful son to Richard Hoggart's The Uses of literacy (1957), and seeks to update this foundational cultural studies text by examining the contemporary concerns of multimedia and digital communication. Through its eight chapters, Hartley's book covers a number of topics, several of which seem unrelated to the titular issue of "digital literacy". The first chapter is probably the most valuable for teachers, in that it suggests that educational institutions must teach digital literacy skills, and that these skills must necessarily be taught informally. Rather than admonishing students for their "inappropriate" use of Facebook or YouTube while in class, educators can usefully take advantage of the of the existing peer-to-peer knowledge networks of their students.
\end{abstract}

\section{Review}

John Hartley's The Uses of digital literacy is the respectful son to Richard Hoggart's The Uses of literacy (1957), and seeks to update this foundational cultural studies text by examining the contemporary concerns of multimedia and digital communication. Through its eight chapters, Hartley's book covers a number of topics, several of which seem unrelated to the titular issue of "digital literacy". The first chapter outlines the shift in cultural studies to emphasise the popular, everyday elements of culture from the insider, "emic" perspective of the individuals who engage in it, rather than the ivory-tower academic as was seen in the earliest work of the Birmingham School. Hartley details the changes in literacy as we have shifted from a "read-only" culture to a "read-write" culture, and notes that education systems must absolutely adapt to these new conditions in order to remain relevant to the youth who engage in these practices: that is, educators must work to understand the "emic" perspective of the students. This first chapter is probably the most valuable for teachers, in that it suggests that educational institutions must teach digital literacy skills, and that these skills must necessarily be taught informally. Rather than admonishing students for their "inappropriate" use of Facebook or YouTube while in class, educators can usefully take advantage of the existing peer-to-peer knowledge networks of their students.

The remaining sections of the book do not deal explicitly with educational paradigms, but instead work to update several of the theoretical underpinnings of cultural studies for the digital era. The concept of "industry" is engagingly critiqued in the second chapter: Hartley notes quite astutely that as the concept of the audience has changed to include consumer-generated content, then the concept of the media industries (previously, the only purveyors of content) must also be updated as well, and outlines

The International Journal for Educational Integrity is available online at:

http://www.ojs.unisa.edu.au/journals/index.php/lJEl/

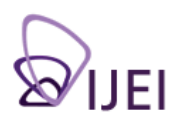


the characteristics of the new and more dynamic "creative industries". The concept of audiences and representation is discussed in the third chapter. Hartley notes that "everyone with access to a computer can not only 'sing' for themselves, they can also personally publish the results to everyone else" ( $p .83)$. While noble, this statement does not consider the important issues of access to digital technology and internet. While the majority of individuals in metropolitan areas of Western nations have some degree of access (and this is not guaranteed), the emancipatory potential of "readwrite" media does not extend to include to those in developing countries, regional or rural areas, or those without the necessary funds to own a computer and have access to broadband internet.

The fourth chapter, "Uses of YouTube", will be of interest to educators as it deals with some of the implications of using this particular digital technology in an educational setting. Hartley points out that contemporary youth have learned from experience that formal education is not designed to instruct them in digital literacy, but rather to protect them from inappropriate content (p.105). Schools, he writes, have become increasingly regulated and distanced from the daily lives of the youth, while media and popular culture are intimately involved in their lives. This rigid separation of formal, institutionalised education and ad-hoc, peer-to-peer networks must be broken down if teachers are to keep pace with their students.

Digital storytelling is offered up, in the fifth chapter, as a way to bridge the gap between the world of professional media and "everyday cultural practice" (p.122). "Here, however," argues Hartley, "the term refers only to the practice whereby 'ordinary people' participate in hands-on workshops using computer software to create short personal films that privilege self-expression" (p.122). It is unclear what type of workshops Hartley refers to, but based on the examples, I believe it refers to community storytelling projects. While acknowledging that the YouTube community is mostly self-taught and community-driven, Hartley argues that the skill of digital storytelling must be taught through a workshop, and the assistance of some sort of instructor or facilitator is needed as well. Rather than privileging the expertise of the instructor, though, dialogic learning should be employed to combine the intelligences of the people and the facilitator: "In short, the expertise of the filmmaker or documentarist when coupled with a 'parallel' intelligence from the lay population can result in new and compelling stories that do credit to both parties" (p.135).

The sixth and seventh chapters of the book seem to shift away from this issue of digital literacy, however. Chapter Six outlines the relationship between journalism and cultural studies, in particular the roles of power and democracy in journalism. The impact that digital communication technologies (such as blogs and social network sites) have had on journalism as a practice seems glossed over. The Seventh chapter, while interesting, seems somewhat out of place in a volume on digital literacy, as it deals with semiotics and fashion, particularly the launch of Vogue Magazine into China.

The concluding chapter provides a history of the cultural studies movement and details how the discipline has changed since its inception by Hoggart. In particular, Hartley calls for studies that look for the large-scale, macro levels of theoretical conception to replace the now abandoned Marxist framework upon which cultural studies was founded, as the discipline is limited by its emphasis on micro level analysis. While engaging and well-written, The uses of digital literacy would perhaps not be explicitly useful for educators interested in new media and academic integrity. Only one new media technology (YouTube) is considered in any great depth, and while the importance of digital literacy is acknowledged for creative innovation, only the most general suggestions are offered for implementing these new forms of literacy in classrooms, and questions of what impact digital literacy might have on academic integrity is lacking. Also, I believe it is valuable not to over-estimate the existing skills of the so-called "digital native" students (Prensky 2001) without evidence: just 
because they have grown up with the Internet does not necessarily make students computer-savvy. Despite these shortcomings, this book provides a necessary update to the field of cultural studies and would be recommended for scholars interested in the field.

\section{About the reviewer}

Katharina Freund is currently completing her $\mathrm{PhD}$ dissertation in media and communication at the University of Wollongong in Australia. Her research deals with an online community of (mostly) female video editors who construct music videos using film and television footage that often convey meanings not intended by the original creators. Katharina also teaches in digital communications and researches pedagogy in virtual worlds.

\section{References}

Hoggart, R. (1957). The uses of literacy: Aspects of working class life. London, Chatto and Windus.

Prensky, M. (2001). Digital natives, digital immigrants. On the horizon 9(5). Retrieved 1st December 2010 from: http://www.marcprensky.com/writing/Prensky\%20-\% 20Digital\%20Natives, \%20Digital\%20Immigrants\%20-\%20Part1.pdf 